\title{
"Factors explaining the adoption of mobile marketing in Cameroon: Exploratory study on the use of SMS as method of transmission of social information"
}

\author{
MBIADJO FANDIO Faustine Mimosette* and DJEUMENE Paul
}

Marketing Department, University of Ngaoundere, Cameroun.

Received 31 October 2014: Accepted 2 February, 2015

\begin{abstract}
Mobile marketing is getting an increasingly powerful presence in the communication channel of tomorrow, given its increasing use worldwide. In the Cameroonian context, this method is therefore increasingly used for the transmission of social information. The goal of this exploratory research is to identify and describe the factors that would likely affect the adoption of mobile marketing by advocates of social issues in Cameroon. A Technology-Organisation-Environment framework of the contextual influences on the adoption of technological innovation is used to interpret an analysis of four advocates of social issues and the use of mobile data. The results show that the importance of the objectives sought, the benefits foreseen, were the most important factors influencing adoption of mobile marketing. Other factors that appeared to influence the adoption of mobile marketing included the influence of partners, the perception of receptiveness from the target population and the compatibility with the traditional means of communication. The complexity seemed less important for these adopters; it was not mentioned by the majority.
\end{abstract}

Key words: Mobile marketing, social SMS, adoption of mobile marketing, advocated of social issues.

\section{INTRODUCTION}

Mobile marketing, defined as the use of the mobile channel as a means of marketing communication (Leppaniemi et al., 2006), is a rapidly developing concept given the increasing use of the mobile telephone. The concept ensures a more precise targeting of the consumer wherever they are and in all their movements. For marketing professionals today, the concept has become an interesting element which is to be integrated in a communication campaign. Mobile telecommunication in Cameroon is equally witnessing a significant evolution and touches an important part of the population. Actually, according to ITU (International Telecommunications Union), the penetration rate of mobile telephone went from $0.68 \%$ in 2002 to $9.39 \%$ in 2004 , and later to $24.45 \%$ in 2007 and $32.6 \%$ in 2008 . The increasing use of mobile telephone by the Cameroonian population clearly shows the importance given to this channel as far as transmitting information is concerned.

With this, it is clear that this channel is increasingly used in Cameroon for the transmission of social

*Corresponding a uthor. E-mail: mimosa fandio @yahoo.fr, Tel: 23777229616.

Authors a gree that this a rtic le rema in pemanently open access under the terms of the $\underline{\text { Creative Commons }}$ Attribution License 4.0 Intemational Lic ense 
information. This is illustrated by the messages sent following partnerships between some public ministries (the Ministry of Public Health, the Ministry of Water and Energy...), some NGOs (UNICEF, WWF, KO palu ...) and mobile telecommunication companies (MTN, Orange and Camtel): "SOS cholera: 3 diarrhoea ? Vomiting? Quick! Mix a sachet of ORS in 1 l of water, drink bit by bit and go to the hospital. WHO/Orange Funds » or »World environment day: Together against climate change. Our planet needs us. Message from MINEP, WWF and MTN Foundation"; message sent to several MTN subscribers in Cameroon on 05/06/2009.

Resorting to the mobile channel as means of communicating information is a new phenomenon in the Cameroonian context, same as the transmission of social messages. Hence, advocates of social issues in Cameroon have difficulties adopting mobile marketing. A number of studies have examined the acceptability of mobile marketing and mobile services by the consumer such as (Bauer et al., 2005; Dickinger et al., 2004; Gauzente, 2008, Tsang et al., 2004). This suggests that the acceptance of SMS (short message service) advertising is beginning to grow and may have the potential to become an important new mode of direct marketing communication. However academic research on mobile communication, unlike that on internet advertising has seen only modest growth perhaps because the medium is new and uncertainty remains as to how it will evolve. This makes it difficult to obtain reliable and valid dataset to examine consumer and firm adoption behaviour regarding mobile communication. Adoption by companies has mostly been tackled in the literature by the study of both internal and external factors which affect the good running (managerial, environmental, organisational, technological, cultural factors ...). It is in this light that Rogers (1995) pointed out that managerial, environmental, organisational and technological factors have an impact on the adoption of innovation by companies. Likewise, Okazaki (2005) and Okazaki and Taylor (2008) based their explanation of the intention to adopt mobile marketing (especially advertising SMS) by European firms on various environmental and managerial factors.

The idea that mobile marketing can transform the way communication and advertising goes is more and more accepted. But the mobile channel's growth as a marketing and advertising vehicle has been so fast that some of the world's most advanced marketers are yet to determine how to fully embrace it; not because they do not want to but because of inadequate experience as noted by Friedrich et al. (2009). Also, mobile marketing being a new phenomenon, it is necessary to identify the factors taken in account in the choice of the channel for communication campaigns on social issues in order to have the point of view of those who have experience on the domain. Consequently, the objective of this research will be to identify and describe the factor which would likely influence the adoption of mobile marketing for the transmission of social information by advocates of social issues in Cameroon. This article sets out to understand the phenomenon of adoption of mobile marketing by identifying the explanatory factors of its use by the advocates of social issues in the Cameroonian context; and to direct the choices of both social and public decision makers on the choice of their communication strategy.

Given that the adoption of mobile marketing by advocates of social issues is not yet well developed, we used an exploratory analysis through case study to provide analysis from 4 advocates of social issues who are already using mobile telephones within the framework of some of their communication campaigns. We therefore based our research on the adoption of e-commerce by organisations to develop our analysis. In the next section, we will present a conceptual framework based on technological, organisational and environmental factors which influence the decision to adopt an innovation. We will later present the methodological guideline adopted in this research, followed by the 4 cases studied. The last part of this article will be a synthesis of the conclusions got from comparing the various cases and will discuss the implications for research and for the practices in the domain.

\section{RESEARCH FRAMEWORK}

Mobile marketing is an increasingly used concept in marketing. It is an already well implemented concept in Europe with the evolution of technologies. In Cameroon, the concept is still in an embryonic state. In this section, we will present mobile marketing in general, and its evolution in the Cameroonian context.

\section{Mobile marketing}

The increasing penetration level of the use of mobile telephone in the world, notably in developed economies since the $90 \mathrm{~s}$, and the mobile technological breakthroughs and means of communication are some of those elements contributing to the birth of the mobile marketing concept.

\section{Definition and characteristic of mobile marketing}

Mobile marketing is a new marketing concept which has known many definitions. However, even with the existing literature on the domain, a consensus has still not yet been arrived at regarding the definition as noted by Varnali and Toker, (2010) and Leppäniemi et al. (2006).

The Mobile Marketing Association (MMA) (2008) defines mobile marketing as 'A set of practices which enable organisations to communicate and collaborate 
with their public in an interactive and pertinent way through any mobile device or network'.

Other research works enable us interpret the role of marketing more specifically. Notably that of Scharl et al. (2005) for who mobile marketing consists of the use of a wireless devices to provide to consumers, at the appropriate places and time, personalised information promoting goods services and ideas, thereby generating value for all stakeholders. According to Bauer et al. (2005), mobile marketing is the use of mobile telephone as a channel for the transmission of commercial content to consumers. The specificity noted here is the fact that mobile marketing makes reference to the use of a mobile channel for the transmission of personalised information to consumers.

On the other hand, other research considers the transmission of information to consumers via the mobile channel as mobile advertising. In this light, Leppäniemi et al. (2004) defined mobile advertising as any paid message communicated by mobile media aimed at influencing the attitudes, intentions and behaviours of those to whom the messages are directed. Likewise, Haghirian and Madlberger (2005) noted that mobile advertising consisted of using interactive wireless media such as mobile telephones, for the transmission of personalised advertising messages to consumers, with the main aim of promoting their goods and services.

However, the use of a mobile telephone for the transmission of information to consumers is not only limited to the terms "mobile marketing" and "mobile advertising". For other writers, it rather corresponds to wireless advertising or wireless marketing.

The definition adopted within the framework of our research is that of Leppäniemi et al. (2006) who defined mobile marketing as 'the use of the mobile channel as means of marketing communication'. This definition gives room for the integration of the transmission of both commercial and social information.

Mobile marketing has several characteristics which make it a complete channel of communication. Many writers have shown interest in the characteristics of a communication by mobile marketing (Anckar and D'Incau, 2002; Bauer et al., 2005; MMA, 2008; Varnali and Toker, 2010). The most commonly quoted are: the intimate and the interactive nature, the omnipresence, the personalisation, the localization and the accessibility.

\section{The main tools and strategies of mobile marketing}

Several tools are used for marketing purpose, that is, they enable the transmission of information through the channel of a mobile telephone. The most important are the SMS and the MMS. In the field of mobile marketing, the main tool lies on the sending of text messages, SMS (Gauzente, 2008). The transmitted messages have a maximum content of 160 characters.

The MMS or multimedia message service is an emission and reception system of multimedia messages via mobile telephone. Its capacity goes beyond that of the SMS which is limited to 160 characters, and enables the transmission of photos, audio recordings and video messages. However, given the high cost of the service and the fact that not all terminals can send and receive multimedia messages, the MMS is less used in mobile marketing, notably in the Cameroonian context.

Sending messages to consumers via the mobile channel means choosing between two strategies: the push strategy (push marketing) and the pull strategy (pull marketing).

The push strategy (push marketing): This is traditionally the most adopted model for sending text messages by marketers as highlighted by Haig (2002). A push marketing campaign assumes that the consumers has given the approval or has subscribed to receive information on offers or updates of a company through the channel of SMS (Leppäniemi et al., 2004; Haig, 2002).

It equally corresponds to receiving unsolicited messages which the sender believes can catch the interest of the receiver. An example is the social messages sent on mobile telephones. The targeted populations have generally not received any request from the advocates of social issues aimed at seeking their approval on receiving messages. But given the nature of this information, the advocates of social issues assume that the messages can be judged pertinent by the receivers.

The pull strategy (pull marketing): According to Leppäniemi et al. (2004), it corresponds to sending messages whose content or services have been previously requested by the users. The main idea underlying most pull marketing campaigns is the instant access to information or services which mobile users wish to receive (Haig, 2002). These different strategies are used by different actors of the mobile marketing sector in order to reach mobile users in the appropriate manner.

\section{Factors of the adoption of a technological innovation}

The Technology-Organisation-Environment framework model proposes that organizational innovation is influenced by three elements namely the perceived attributes of the technological innovation, the organisational characteristics and environmental factors.

\section{Technological factors}

Technological factors have always been the central point as far as adopting innovation is concerned. Actually, several adoption theories have show cased technology related advantages as a factor influencing the adoption of an innovation. This is the Innovation Diffusion Theory 
(IDT), the Technology Acceptance Model (TAM) and the Unified Theory of Acceptance and Use of Technology (UTAUT). Within the framework of the IDT, Rogers (1995) exposed the elements that favour the adoption of technological innovation, notably the related advantages. The relative advantages show the benefits and costs that result from adopting and innovation. Rogers noted that the constitutive elements of the relative advantages are: economic returns, low implementation cost, a reduction of discomfort, social prestige, gain in time and effort, and the rapidity of the response. The concept of relative advantages goes in line with that easy usage of Venkatesh and Davis (2000); and that of expected performance and prepared effort by Carlsson et al. (2006) through UTAUT.

Moreover, Tornatzky and Klein (1982) found that three perceived attributes of the technology innovation were consistently associated with innovation adoption behaviours: the relative advantage of an innovation over its predecessor; its compatibility with the organization's needs and existing systems; and its complexity to understand and use.

Within the framework of mobile marketing, technological factors represent one of the most important factors.

This actually has a significant impact on the adoption of mobile services for both the sender-actors (the advocates of social issues) and the receiver-actors (the target populations) of the messages. Given that presently, mobile marketing mainly lies on sending text messages (SMS), its adoption has been determined by the fact that associated technologies to mobile communication provide the necessary infrastructure to enable the consumers send and receive SMS (Okazaki, 2005). Likewise, Okazaki and Taylor (2008) have noted that the intention of a firm to uses mobile publicity is positively associated with the perception of sufficiency of the technological environment, that is, the perception of many consumers who have adopted this technology which enables them to receive SMS.

The advantage of SMS lies on the fact that most mobile telephones can send and receive messages. With the remarkable breakthroughs in the development of mobile telephones, the latter have more functions like the internet, the sending of videos (mms). However, these recent functions are only accessible on multimedia telephones which are not very much used.

Technological advantages of mobile marketing can be seen at two levels: perceived benefits and compatibility.

\section{Perceived benefits}

Perceived benefits in adopting a new technology have been identified as a critical factor in the adoption of information technologies by small businesses. When companies do not see the potential benefits of adopting a new technology, they tend not to adopt (lacovou et al., 1995). The perceived advantages refer to the recognition of management of the relative advantage which the adoption of a new technology can provide to companies (Lertwongsatien and Wongpinunwatana, 2003)

Perceived benefits in mobile marketing focus on the gains in terms of time and space. As underscored by Gold et al. (2010) SMS enables you to simultaneously send messages to multiple recipients in a rapid diffusion, but also they are delivered immediately. Gauzente (2008) noted that the rate at which people read an SMS varies between 95 and 100\%. Actually, everyone instinctively reads a new message when it arrives in his telephone. The use of SMS therefore enables you to create a special relationship between the sender and the receiver of the message (Okazaki, 2005).

Perceived benefits here also refer to the perception of how easy it is to use the technology. The advantage of SMS is that it is simple and easy to use.

\section{Compatibility}

This case is all about ensuring that the use of SMS is compatible with the objectives that the advocates of social issues set for themselves. Similarly, it must be compatible with the channels already used in the transmission of social information.

\section{Organisational factors}

Organisational factors that depend on the structure of the organisation present were analysed by several authors within the framework of the adoption of e-commerce by organisations (Sparling et al., 2010; Okazaki, 2005; Okazaki and Taylor, 2008).

Although in the course of their work on the adoption of mobile advertising through SMS by multinationals Okazaki (2005) and Okazaki and Taylor (2008) do not elaborately analyze the impact of these factors; it appears important to come back to it within the framework of our work given the specificity of the organisations we work with.

Chau and Tam (1994) found that the organisational context relates to the structure and processes of an organisation that limit or facilitate the adoption and implementation of innovations. Organisational factors generally represent the characteristics of an organisation and they help explain the adoption of technology as pointed out by Sparling et al. (2010). These organisational characteristics are the size of the organisation, organisational ability, willingness to change, organisational and cultural compatibility etc. We will limit our work to the analysis of a few relevant features given the specific context of our study notably the industry.

\section{Business sector}

The business sector in which an organisation is found will 
influence their adoption of new communication technologies. In this regard, Rao and Troshani (2007) noted that the product or service that an organisation sells will have a significant influence on the suitability of the adoption of mobile marketing for the communication of the product or service.

Similar findings were noted in the field of mobile marketing. However, these conclusions are more about the features of the product / service on which the communication is based. Rao and Troshani (2007) noted in this regard that the product sold must be relevant. Likewise, it has also been argued by several authors that the mobile channel is more suitable for low-budget commercials and for products and / or services which are sensitive to specific contexts such as the purchase of movie tickets, bank transfer, newspapers, weather services (Barwise and Strong, 2002; Mort and Drennan, 2002; Leppäniemi and Karjaluoto, 2005). Mobile marketing is also important in targeting young people (Scharl et al., 2004).

The business sector thus determines the adoption of mobile marketing and even more the objectives based on this adoption. As earlier noted, NGOs and government departments who have a social mission make use of mobile marketing to send social messages. Lindon (1985) noted that NGOs are organisations which have a constant selfless social vocation to work for the welfare, safety or the survival of the company as a whole or of certain social categories. To fulfil this mission, they must ensure that they transmit information to the people to educate them on various subjects and especially raise awareness.

This awareness has a dual purpose according to Gold et al. (2010). First to communicate new information or specific information; and secondly to remind the people what they already know, that is, to refresh their memory on supposedly already acquired knowledge.

In social marketing, the watch word in many campaigns is education and information rather than sales; and is directed towards attitudes rather than action. Behaviour change is the ultimate goal of social marketing (Barach, 1984).

Social awareness here can meet the educational objectives pursued by NGOs in achieving their missions and fight against various diseases that destroy the lives of the target population daily. Communication programs therefore often reflect a summons to raise awareness among the public to adopt healthy behaviours (Barach, 1984). At this juncture education strategies are most used.

Achieving these goals also requires the adoption of an effective communication channel. This is because it will not only get the message across, but also reach a larger portion of the target population. Sender-actors agree that the mobile telephone with the many benefits that it carries is the most appropriate tool today for the transmission of information to the people so as to ensure them better coverage.
We have seen that this business sector best explains the adoption of mobile SMS since it helps achieve more easily the goal of social awareness pursued by the advocates of social issues in Cameroon.

\section{Environmental factors}

Environmental factors are factors that are external to the organisation, but that positively or negatively influence their objectives. Environmental factors generally include elements related to culture, technology and institutional rules. As part of our work, these factors relate more to the influence of partners and perceived responsiveness of target populations.

The influence of the partner: several categories of actors are involved in the process of sending text messages to target populations and it is precisely the facilities offered by the mobile companies which make this process easier. Indeed, NGOs and ministries design messages and mobile telephone companies with which they are partners are responsible for sending them. They provide the client files or composed file of subscribers and it becomes easier.

The perceived receptiveness of target populations: Since the success of every marketing action developed by a company depends on the consumer's attitude towards this action, similarly, the attitude of the advocates of social issues in respect to mobile marketing will largely depend on the their perception of the acceptability and responsiveness of consumers to the social messages they receive by this means of marketing action. Actually, as pointed out by Vatanparast (2010), in each event if marketers want to effectively use the means of communication offered by the mobile channel, they must necessarily understand how mobile telephone users perceive and evaluate mobile SMS as a source of advertising or transmission of social information. In the same light, Okazaki and Taylor (2008) found that managerial intention of companies to use the mobile channel as a means of communication is connected to the way that SMS advertising is perceived and accepted by consumers. Given the importance of the private aspect in the acceptability and adoption of mobile marketing, it appears that consumer willingness to adopt the social message is an essential choice criterion for companies which enable them to assess whether or not they should use mobile marketing. It appears that responsiveness and even more its perception by potential users of mobile marketing is an essential factor to the adoption of the previous by the latter (Figure 1).

\section{RESEARCH METHODOLOGY}

The research objective was to provide an empirical exploration on the antecedents behind the adoption of mobile marketing 


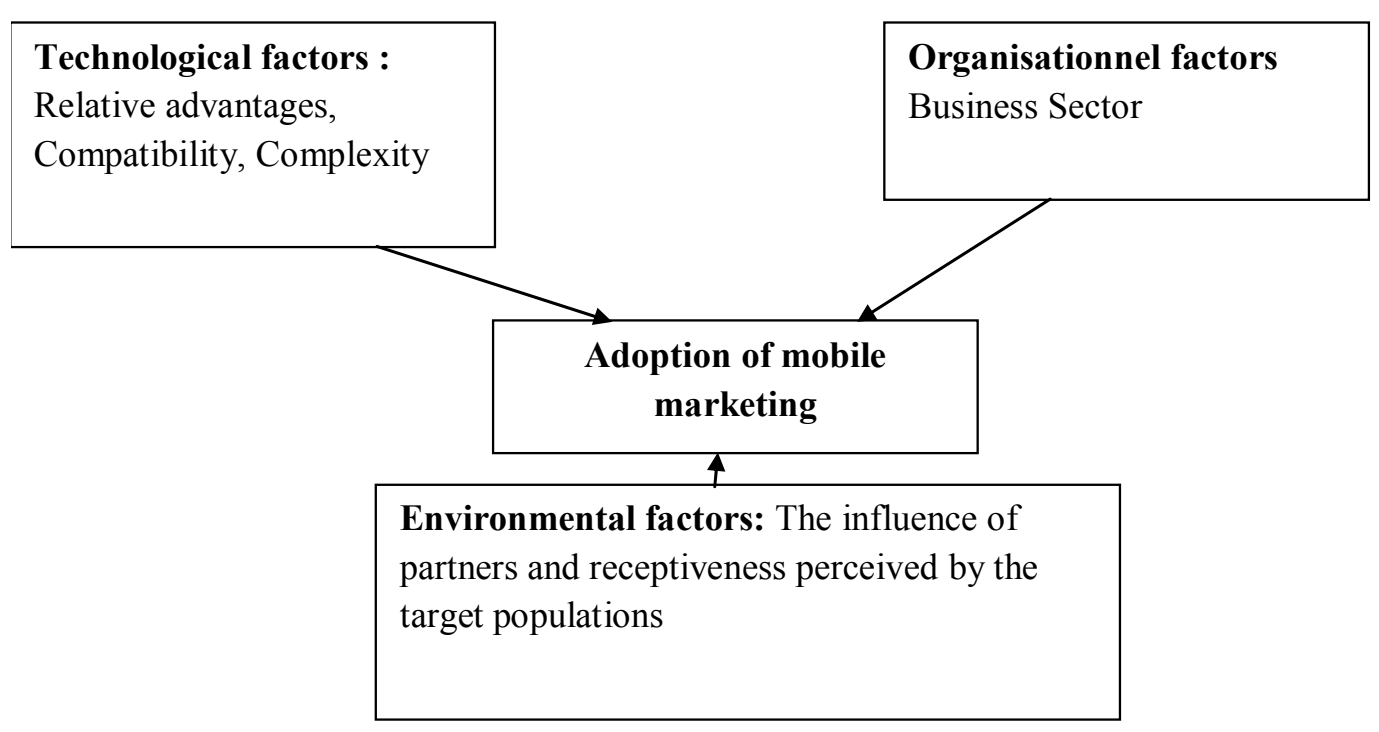

Figure 1. Contextual model of the influences on the adoption of mobile marketing. Source: adapted from contextual influences on mobile commerce technology (Doolin et al., 2008).

technologies by organisation in their communication strategy in order to transmit social information. Because our understanding of this technological innovation context is relatively undeveloped and lacks a strong theoretical base, we use an exploratory case study approach. We applied the preliminary model of mobile commerce technology adoption which was contextualize to mobile marketing to four cases studies of adopters of mobile marketing mainly advocates of social issues in the Cameroonian context. More so, case studies better orientate our focus on the contextual conditions of the adoption of mobile marketing (Yin, 2003), because we focus our attention not only on the case study but also on the processes and phenomena that allow highlighting. The principle of theoretical enrichment has guided the selection of cases used to study more general phenomena. Cases were then selected for their potential for learning as recommended by Ayerbe and Missonier (2007). To satisfy both internal and external validity conditions as recommended by Ayerbe and Missonier (2007), we opted for two tactics in data analysis: "pattern matching" and the construction of explanations which is a special case of pattern matching. The objective here is to analyse the case data by building an explanation about the case that is a set of causal links. Therefore, in order to work towards an increasing generalization, our data analysis will go through the facts shaped, intermediate theory and the general theory.

Based on the work of Huang (2011) on the identification of actors in the value chain of mobile marketing, we have identified in the Cameroonian context three main categories of stakeholders namely government ministries, NGOs and the mobile telephone companies. This categorization has guided us in the selection of individual cases.

Our primary source of information was semi-structured interviews conducted in 2012 with marketing and / or communication managers of these advocates. During these discussions between $45 \mathrm{~min}$ and $1 \mathrm{~h} 30 \mathrm{~min}$, the interviewees were asked, following thematic interview guide, to tell us what they think about mobile marketing notably the reasons for its use, the benefits that they get, the objectives of its use and the means implemented to improve on the responsiveness of target populations. The interviews were fully transcribed and content analysis was conducted. The data from these interviews were supplemented with secondary data including data available on the various organisations and their activities.
Thus, in the course of this research before presenting the results of this content analysis, we will first present the case of mobile marketing campaigns in the Cameroonian context.

\section{The case of mobile marketing campaigns and the factors identified}

In our work, we studied 4 cases of mobile marketing campaigns that have been developed by four different organisations, to which we assigned letters as names for confidentiality reasons.

\section{The case of organisation $A$}

Organisation A is a non-profit organisation which was established in 2006 and intended for the transmission of information and awareness information to the Cameroonian people on various social problems they face in everyday life (poverty, disease, protection against the environment, health, education etc). It mainly works with other NGOs, some public ones and with these institutions, ensures the transmission of information through the mobile telecommunication company to which it is attached. This organisation which can be considered according to Rogers (1995) as innovative is one of the first to have used the mobile telephone for the transmission of social information through SMS. Thus, it has been involved in various sensitisation campaigns by sending text messages such as "World Malaria Day: united against malaria," or "Nature: our heritage, our well-being. Preserve it"

The most important campaign which is the fight against malaria took form by the use of all channels in communication notably the television, the radio and posters. The campaign was accompanied by the distribution of insecticide-treated nets. The campaign was aimed at eradicating malaria in Cameroon especially in the most affected areas. Our interview with the communications officer of the organisation, which lasted one hour, enabled us to note the importance attributed to this communication channel for their different campaign. In this order, we actually noted that setting-up such a campaign depends on several factors among which, the type of message you want to convey. The target population varies according to campaigns. Our respondent noted in this regard that "the target population varies depending on the magnitude of the 
targeted campaign. It can cover the entire national territory within the framework of a national campaign, same as it can be restricted to a specific region within the framework of a regional campaign." Therefore "transmitted messages are either the result of a specific event such as the cholera epidemic or a more general event such as messages sent during the World AIDS Day".

\section{Technological factors}

Organisation A clearly perceives a relative advantage in their mobile data solution that is the use of mobile in the transmission of social information to design or target population. The facilitating conditions offered by the use of SMS are an important point. Our respondent noted that 'it is accessible because all telephones can receive and send SMS'. It is then the assurance to touch a large audience of the population targeted. Furthermore he added that "the use of the latter does not cost anything, because our partners provide us with databases."

Moreover mobile marketing is not an isolated communication channel; "it is a continuum of other communication channels and they are complementary."

\section{Organisational characteristics}

The advocates of social issues evolved on a sensitive sector which is the social domain. Objectives set, given their corporate name, are completely different from commercial company.

Organisation A as non-profit organisation is concerned with the well-being of populations she addresses. Therefore, the use of an efficient and appropriate communication channel is necessary to reach the objectives set. For the head of communication unit of this organisation, the use of SMS enables one to achieve two main goals namely 'wider coverage of target' and the transmission of customised information. The widespread identification of the various users of mobile telephone by the identification of the owners of SIM cards permits the sending of messages according to needs because it is possible to know where most of these owners live in the majority of cases. Thus, targeted campaigns have been conducted in specific areas depending on the problem that they encounter.

\section{Environmental factors}

For organisation $A$, the environment played an important role in the use of SMS for the transmission of social messages. This influence comes partly from partners. Consequently, during our interview, the head of the communication unit of this organisation acknowledged the importance of partners in constituting the files that is for all subscribers who will receive messages. He highlighted that "partners provide databases".

The second influence is from the target population. Their perceived responsiveness has a major impact on the use of this communication. In order to get the attention of the receiver and create a positive attitude, "messages are designed precisely and concisely." More so "simplicity in message design meets the need of understanding and favourable assessment thereof by the recipient." Similarly, we found that the frequency of message sending depends on the magnitude of the phenomenon. Some messages are thus sent several times, while others are not. However, the results after the campaigns are got more from observation and they help to note changes in the behaviour of the target population.

\section{Case of Organisation B}

Organisation B is one of the first to have used mobile telephones for communication campaigns. In fact, the latter was used in the early 2000 s to provide information on neonatal tetanus. But given the low penetration rate of mobile telephone habits in Cameroon's population at that time due to its high cost, this communication has experienced a dead phase only to strongly get back to its feet with the present outburst which the use of mobile telephones is experiencing.

Organisation B is very involved in virtually every communication campaign in terms of health. They have therefore participated in many campaigns including campaigns on cholera, on the prevention of cardiovascular disease (" diabetes and hypertension health alert: these diseases can affect everyone, it concerns us all."), on malaria ("you can only get malaria from a mosquito bite. Protect you and your family, use a mosquito net") to name but a few.

We were able to have a $1 \mathrm{~h} / 30 \mathrm{~min}$ discussion with Head of the communication unit of this organisation. This interview enabled us to bring out technological factors, organizational characteristics as well as environmental factors which influence the adoption of mobile marketing.

\section{Technological factors}

The new mobile solution as mean of communication was perceived very well by organisation $B$ due to its benefits. It has been proven that sending SMS is easy to use. There is no need of technical operation when using a SMS like when using e-commerce with the need to master the use of computer and internet. The head of communication unit emphasised that "Cameroon has about 10 million mobile telephone users. Sending a message via this channel is a guarantee that it will be read by a large percentage of the population". Also, the use of this canal is cheaper than the others; it is almost free of charge.

In the same manner, using SMS makes you get closer to the population. Another benefit included the possibility bringing the sender and receiver closer by engaging them in a unique relationship where the receiver feels personally addressed. So, the information provided via the mobile telephone has created a particular relationship between the sender and the receiver. The Head of Communication Unit then noted that "SMS favours proximity communication". Resorting to the use of SMS appears to be equally related to the use of traditional communication channels, as our respondent rightly put, "this communication channel also complements others channels". The use of mobile marketing appeared to be a particular channel because of its advantages, the relation it creates between two members of the communication chain and its compatibility and complementary with the other communication channels.

\section{Organisational characteristic}

The mobile marketing solution was deliberately developed in a way that permits achieving specific goals. The benefits named above matched the organisation $B$ expectations which are "communication for change which can help to sensitise the population about the problem raised" and "transmission of customised information". Moreover, sending a message via this channel is a guarantee that it will be read by a large percentage of the population.

\section{Environmental factors}

The mobile telephone companies are an important partner for organisation B. Actually, the latter enables them to send messages free of charge via their network given the contract relationship that unites them as well to the Ministry in charge of Post and Telecommunications. Our respondent noted that "the partnerships that 
bind us to MTN and the Ministry of Posts and Telecommunications facilitate our task. We are responsible for designing the message within the limits imposed by SMS and they take care of all the technical aspects."

Another environmental factor which influences the adoption of mobile marketing by organisation $B$ is how she perceived the responsiveness of target population. Elements such as the sending frequency and timing for sending messages are defined so as not to irritate recipients, and the messages sent are simple and interesting enough to attract the attention of the target population. "These precautions taken beforehand help us ensure a relative acceptability by the population and a good return in terms of compliance with the prescribed measures," since most of these messages are related to the occurrence of specific events as pointed out by our respondent "some of our communication are related to multi-year communication plan relating to malaria" or "the conditions for sending messages is usually a feature of general events and the need for specific events." Also the design of the message is done by the communication unit and is defined within the limit number imposed in terms of the SMS characters $(160$ characters).

\section{Case of Organisation C}

Organisation $\mathrm{C}$ can be considered a late adopter according to Rogers (1995) as its use of the transmission of social information is very recent. In fact, the organisation started by the "wash" initiative which was a project to eradicate the cholera epidemic that has raged in Cameroon in 2010. Awareness incorporated methods of control and prevention against the disease. The instructions given were mainly on compliance with hygiene on the one hand notably: Wash hands with soap and water before meals and after leaving the toilet, wash the food we consume, use latrines built far from water points. On the other hand, the recommendations focused on water treatment before consumption, and on going to a hospital from the first signs of vomiting or diarrhoea. And messages such as "SOS cholera: 3 diarrhoeas? Vomiting? Quick! Mix one packet of ORS in a 1 l of water, drink gradually and go to the hospital "were sent to the Cameroonian population to inform and educate them.

Moreover, we had a 45 min interview with the head of communications of the organisation. It is clear from this discussion that the use of SMS through communication campaigns was because of its numerous benefits.

\section{Technological factors}

At Organisation $\mathrm{C}$, the use of mobile marketing in order to transmit their messages was implemented for its numerous benefits. The first benefit that we noted down was the easy use of SMS due to the fact that the owners always have their telephone on them. This implies that on sending a message you have assurance that it will be received and read by the owner. Also, the SMS function exists in every type of mobile telephone since they can all send and receive messages, you do not need a specific telephone to receive messages. In fact, our respondent noted that "the telephone has become fashion and is always on its owner, sending SMS ensures greater coverage for all telephones have this feature".

Another advantage is the financial benefit provided by this type of communication for this organisation. The financial benefit was highlighted as shown in this reflection of our respondent "SMS is less expensive than other communication channels and is almost free for us given the partnerships we have with a mobile telephone company". Moreover, this communication channel permits the use of other communication channels because they are complementary and compatible "in addition it can complement the action of other communication channels that we used to use". The mobile telephone thus appears to be an easy to use channel and offers many advantages.

\section{Organisational characteristic}

The use of mobile marketing through the sending of social information by SMS has enabled Organisation $C$ to improve on the efficiency of his campaign. The importance of the objectives pursued by such use clearly shows it. The main objectives that underlie the use of mobile telephone in a communication campaign are: wider coverage of the target, but also the awareness on various social ills that undermine the welfare of target populations. These objectives have been identified as most important by our respondent.

\section{Environmental factors}

The most important environmental influence on organisation $\mathrm{C}$ adoption of mobile marketing was their partnership with telecommunication companies. These companies facilitate SMS sending. Our respondent observed that "our partners not only provide customer files but also are responsible for sending SMS to their individual subscribers".

Another important factor was their perceived responsiveness of the population targeted. To ensure the responsiveness of populations, the message is already defined in a precise and concise manner, and is sent to either during the corresponding hourly breaks for those who work (1-2pm) or in the evening (7-9pm). These messages equally address a specific and immediate need of the populations as noted by our respondent "because our messages meet a specific and timely need of the population, we are sure that they will be interested and they will put our recommendations to practice. Evidence to that is the campaign for the fight against cholera which has been successful because no case has been registered again." The mobile telephone therefore appears as an effective means of communication.

\section{Case of Organisation D}

Organisation $D$ is a non-profit organisation under the international jurisdiction and like Organisation B, is an innovative organisation because it adopted the SMS in its communication campaigns in the early 2000s. This organisation promoting health in the world is very involved in Cameroon in several campaigns aimed at improving on the well-being of populations, notably through vaccination campaigns. This organisation works closely with other organisations so as UNICEF and the Ministry of Public Health.

So the first awareness campaign on vaccination using SMS took place in 2002 and stated "Vaccinate your children from 0 to 11 months against tuberculosis, polio, yellow fever, diphtheria, measles, tetanus." Since then, several campaigns have been conducted in this direction and they also made use of other communication channels (TV, radio, posters). The most recent is the communication campaign launched at the African Vaccination Week 2013. The following messages were thus sent "Save lives. Notify infirmities. Vaccinate "or" Vaccinated Communities are healthy communities! ". These campaigns target the health of children from 0-11 months and pregnant women. During these campaigns, it should be noted that vaccination is free.

Our $1 \mathrm{~h}$ interview with a staff of the organisation's communication unit enabled us to distinguish the three factors which had an impact on adoption of mobile marketing for the transmission of social messages.

\section{Technological factors}

For organisation $\mathrm{D}$, the use of SMS as communication channel for 
sending of social message comes with some benefits. These benefits are related to its practical character due to its easy usability. The use of SMS is free from any technical complexity. Our respondent then observed 'SMS is very easy to use and more practical'. Moreover, it appears to facilitate the transmission of messages to the target population. One of the benefits of using this channel is the fact that it provides a significant financial gain because the cost is lower and partnerships can make it even easier to send messages to the target population.

Another benefit provided by the use of SMS is its compatibility with the traditional communication channel because SMS is simultaneously used with these traditional communications channels namely radio, television and posting.

An aspect of the complexity of the use of this channel was brought to light. It was about the constraint related to the fact that one SMS can only contain 160 characters. Our respondent noted that "it is at this level that the main difficulty arises because the most important points must be said in a few well chosen words to ensure that they convey exactly what you want".

\section{Organisational characteristic}

The adoption of mobile marketing by organisation $D$ reflects its innovative attitude towards technology innovation in general. For this organisation, the main goal through the use of this tool is "communication for behaviour change."

\section{Environmental factors}

Equally for organisation $D$, there are two important factors which favour the adoption of mobile marketing. On the one hand, we have the partners that played an important role within this adoption. Their partnerships with other and some mobile telephone companies enable them to more easily send previously designed messages placed in their care as our respondent pointed out "we design messages that will be sent with respect to the limit of 160 characters imposed by SMS and send them to our partner who sends to its subscribers."Campaigns are most often national, it is therefore the mobile telephone companies to provide and build the file to which messages will be sent.

On the other hand, the receptiveness of the targeted population is too important. Within the framework of campaigns carried out by that organisation, several elements are set up in advance to ensure the best assessment of the target population in order to reach the objectives. In fact it should be noted that "the messages we design are simple so as to facilitate its understanding by many. It mainly focuses on the terms which clearly portray the problem we want to raise; it is therefore as accurate as possible." However, it should be noted that this use depends on the purpose of the campaign.

From these case studies, the following factors could be identified as explanatory factors of use of mobile telephones for the transmission of social information by advocates of social issues in Cameroon.

\section{The factors identified in the different case studies}

The following are the main factors identified from the above analysis as shown in Table 1.

\section{DISCUSSION}

In this study, we explored the factors which would likely influence the adoption of mobile marketing for the transmission of social information by advocates of social issues in Cameroon. In other words, we wanted to understand the phenomenon of adoption of mobile marketing by identifying the explanatory factors of its use by the advocates of social issues in the Cameroonian context. The exploratory analysis finds out three factors that influenced the adoption of mobile marketing namely technological factors, organisational factor and environmental factors.

By taking into account the interviews conducted in the four cases studied, we have noted that the perceived relative benefits appeared to be one of the most important factors influencing the adoption of mobile marketing in our context. These advantages are particularly associated with technological advantages: perceived usefulness, the fact that all telephones can receive and send SMS, it is a convenient way of sending because the mobile telephone is always on the consumer. The results are consistent with theories and model of adoption notably IDT by Rogers (1995). In the literature, perceived usefulness, perceived utility and relative advantage are analogous. This literature shows that advantage has been shown to have a significant and positive influence on the adoption of new innovation (Tornatzky and Klein, 1982; Hsu et al., 2007). Moreover, this channel permits the creation of a special relationship between the sender and the receiver of the message as noted by Okazaki (2005).

Compatibility with other mobile channels also appears to be an important factor because it does not replace traditional channels, but is an added value, and complements them. This result goes in line with the theories and models of technology adoption where compatibility was considered important and theorized as a direct factor on intention to review the Innovation Diffusion Theory (Rogers, 1995). Many empirical studies have confirmed that the compatibility of an innovation has a positive influence on the adoption of innovation. Compatibility helps reduce risk and uncertainty of adoption and these results on technological factors are consistent with the various theories of technology adoption (IDT, TAM, and UTAUT). Moreover the mobile phone is no longer only a telephone; it has become a personal mobile device that integrates both communication and multimedia functionality.

Contrary to compatibility, the direct effect of complexity is not significant; it therefore means that complexity does not appear to be an important factor.

Factors related to the organisational context that may facilitate or inhibit adoption of an innovation are usually defined in terms of various characteristics of the organisation, its employees and available internal resources (Doolin et al., Haj Ali, 2008). In this study, we have limited the study of organisational factor to the characteristic of the organisation particularly on the sector where the cases studies are evolved. The specific sector namely the social sector leads to specific goals. 
Table 1. Summary of factors influencing the adoption of mobile marketing by advocates of social issues in Cameroon.

\begin{tabular}{|c|c|c|c|c|}
\hline & Organisation A & Organisation B & Organisation C & Organisation D \\
\hline \multicolumn{5}{|l|}{ Technological factors } \\
\hline Relative advantages & $\begin{array}{l}\text { "cost absolutely nothing" } \\
\text { Accessible since all } \\
\text { telephones can receive and } \\
\text { send SMS }\end{array}$ & $\begin{array}{l}\text { Easy use, Enables financial } \\
\text { gain } \\
\text { "SMS ensures proximity } \\
\text { communication" }\end{array}$ & $\begin{array}{l}\text { The owner always has the mobile } \\
\text { telephone on him } \\
\text { All telephones have SMS feature } \\
\text { Cost less }\end{array}$ & $\begin{array}{l}\text { Financial gain } \\
\text { SMS is easy to use hence } \\
\text { practical } \\
\text { Easier transmission of messages } \\
\text { to target population }\end{array}$ \\
\hline Compatibility & $\begin{array}{l}\text { "It is a continuum of other } \\
\text { communication channels and } \\
\text { they are complementary." }\end{array}$ & $\begin{array}{l}\text { SMS complements other } \\
\text { communication channels }\end{array}$ & $\begin{array}{l}\text { SMS complements other } \\
\text { traditional communication } \\
\text { channels }\end{array}$ & $\begin{array}{l}\text { SMS is simultaneously used with } \\
\text { other communication channels }\end{array}$ \\
\hline Complexity & Not mentioned & Not mentioned & Not mentioned & $\begin{array}{l}\text { Difficult to say in a few words } \\
\text { what we wish to transmit }\end{array}$ \\
\hline \multicolumn{5}{|l|}{ Organisational factors } \\
\hline $\begin{array}{l}\text { The business sector } \\
\text { influencing the objectives to } \\
\text { be reached }\end{array}$ & $\begin{array}{l}\text { Wider coverage of target } \\
\text { Transmission of customised } \\
\text { information }\end{array}$ & $\begin{array}{l}\text { Transmission of customised } \\
\text { information Wider coverage of } \\
\text { target }\end{array}$ & $\begin{array}{l}\text { Wider coverage of target } \\
\text { Sensitisation on various social ills }\end{array}$ & $\begin{array}{l}\text { Communication for a change in } \\
\text { behaviour }\end{array}$ \\
\hline \multicolumn{5}{|l|}{ Environmental factors } \\
\hline The influence of partners & 'partners provide databases' & $\begin{array}{l}\text { 'partners handle all the } \\
\text { technical part' }\end{array}$ & $\begin{array}{l}\text { Partners provide client files } \\
\text { Partners handle the sending of } \\
\text { SMS }\end{array}$ & $\begin{array}{l}\text { Partners make sure messages } \\
\text { reach their subscribers } \\
\text { They compile the file of those to } \\
\text { whom messages are sent }\end{array}$ \\
\hline $\begin{array}{l}\text { The perceived receptiveness } \\
\text { of target populations }\end{array}$ & $\begin{array}{l}\text { Favourable assessment of } \\
\text { the people since the } \\
\text { messages are designed in a } \\
\text { precise and concise way }\end{array}$ & $\begin{array}{l}\text { Relative acceptability by the } \\
\text { population and a good return } \\
\text { in terms of implementation of } \\
\text { the prescribed measures }\end{array}$ & $\begin{array}{l}\text { "Because our messages meet a } \\
\text { specific and timely need of the } \\
\text { population, we are sure that they } \\
\text { will be interested and they will put } \\
\text { our recommendations to practice. }\end{array}$ & $\begin{array}{l}\text { The designed messages are } \\
\text { simple and understandable by a } \\
\text { larger number of people who } \\
\text { make up the target population. }\end{array}$ \\
\hline
\end{tabular}

Source: ourselves.

The interviews conducted help us discovered that adoption of mobile marketing was intended to achieve the following main objectives: wider coverage of the target, the transmission of personalised information, communication for behaviour change, awareness of various social ills. The most important goal was the wider coverage of the target. A possible explanation is that it is easier to touch many people through the use of mobile telephone than through other media since it is noted everyone is watching the television at the time the message is broadcasted, talk less of listening to the radio at that moment. To this end, Friedrich et al. (2009) noted that "of all opportunities for marketing made available by new media, the mobile platform perhaps holds the most potential". Thus, we observed that contrary to the objectives sought in the commercial field which is communication to improve the brand image (Okazaki and Taylor, 2008), advocates of social issues are mainly NGOs in partnership with the Ministry of Health and the mobile telephone companies pursuing goals completely different.

The last significant influence concerns environmental factors. These factors are partners influence and the perceived receptiveness of target population. Talking about the influence of partners, it is crucial because it helps make financial profit. Partners with mobile telephone companies not only provide them with client 
databases, but equally help them send their messages free of charge. Thus, we found that the partners, notably mobile telecommunication companies, facilitate message sending since they provide and have the necessary resources. In fact, in addition to sending messages, they provide databases from the list of subscribers. This result is confirmed by Decomble (2009) who noted in his study on "Marketing of mobile services" "It is important to remember the complementarities that exist for mobile service providers between an expertise which guarantees the innovative nature of the offers and the mastery of the client". This influence is equally developed in ecommerce where partnership played an important role.

In addition to the partners, the target population strongly influences the adoption. Indeed, we noted that their perception of this receptiveness is important because several conditions to be taken in account at the beginning of each season to catch the attention of the receivers and generate their interest in the transmitted message. This is so that they not only get the message, but apply the recommendations contained in the message. Okazaki and Taylor (2008) highlight that the managerial intention of companies to use the mobile canal as means of communication is related to the way advertisement SMS is perceived and accepted by the consumers. We also have noted with Lee and Hill (2013) that the type of message have a significant influence on utilitarian perceptions of the receiver. Environmental factors relate to the influence of partners and perceived responsiveness of the target population. These factors have all proven to be important in the adoption of mobile marketing.

\section{Conclusion}

This paper presents an exploratory study on the factors taking into account for the adoption of mobile marketing in transmitting social messages by advocates of social issues in the Cameroonian context. At the end of this research, we have shown that the importance of the objectives, the technological and financial benefits, the influence of partners et also that the perception of responsiveness of the target population have a positive impact on the adoption of mobile telephones as a channel for transmission of social messages by advocates of social issues in Cameroon. Our findings confirm previous study on technology innovation by corroborating the importance of technological factors (relative advantage and compatibility) for innovation adoption. However we did not find evidence that complexity influences the adoption of mobile marketing. We chose a qualitative approach because our study remains exploratory given the newness of this means of communication in Cameroon and the insufficient information on the studied phenomenon which does not permit us to use a quantitative approach. The study of factors which could influence the adoption of mobile marketing by advocates of social issues is a prerequisite for understanding the fast evolving phenomenon of message sending which enables us to follow the evolution of the phenomenon through the attitudes of the population (receiving- actors).

Our study may help managers in both the social and commercial area to better determine their marketing strategies and analyse the factors which are most relevant for them. Also, it could be of help to them in their use of mobile marketing. Finally, a better understanding of the decision-making process of adoption of mobile marketing could help demonstrate the benefits already enjoyed by those who have adopted and thrown light on the factors that influence the adoption.

Data collecting for this case study was conducted through semi-structured interviews on a small scale. It would be appropriate to test the relationships in the conceptual model by a quantitative study on a larger scale. Another approach would be to study the factors which associate with each category of advocate because each of them have a different participation in the process of message sending and has a special place in the value chain of mobile marketing in Cameroon. Finally, it would be interesting to adapt the conceptual model of our research to other mobile applications, to other contexts and other types of message (of different nature) and test it empirically.

\section{Conflict of Interests}

The authors have not declared any conflict of interests.

\section{REFERENCES}

Anckar B, D'Incau D (2002), "Value creation in mobile commerce: findings from a consumer survey", J. Inform. Technol. Theory, Applicat. 4(1): 43-64.

Ayerbe C, Missonier A (2007), "Validité interne et validité externe de l'étude de cas: principes et mise en œuvre pour un renforcement mutual", Finance Contrôle Stratégie, 10(2) :37-62.

Barach JA (1984), "Applying marketing principles to social causes", Business Horizons, july-august 1984, 65-69.

Barwise P, Strong C (2002), "Permission-based mobile advertising", J. Interact. Market.16(1):14-24.

Bauer H, Reichardt T, Barnes S, Neumann M (2005), "Driving consumer acceptance of mobile marketing: a theoretical framework and empirical study", J. Electronic Commerce Res. 6 (3): 181-192.

Carlsson C, Carlsson J, Hyvönen K, Puhakainen J,Walden P (2006), "Adoption of mobile devices/services - searching for answers with the UTAUT", Proceedings of the $39^{\text {th }}$ Hawaii International Conference on System Sciences.

Chau PY, Tam KY (1997). "Factors affecting the adoption of open systems: An exploratory study", MIS Quaterly, 21(1): 1-24.

Decomble B (2009), "Marketing des services mobiles: pour une gestion intégrée des offres innovantes", Revue Française du Marketing, 222, 33-49.

Dickinger A, Haghirian P, Murphy J, Scharl A (2004), "An investigation and conceptual model of SMS marketing", Proceedings of the $37^{\text {th }}$ Hawaii International Conference on System Sciences, USA: IEEE.

Doolin B, Et al Haj Ali E (2008). "Adoption of mobile technology in the supply chain: an exploratory cross-case analysis", Inter.J.E-Bus. Res.4(4): 1-15.

Friedrich R, Grone F, Holbling K, Peterson M (2009), "The march of 
mobile marketing: new chances for consumer companies, new opportunities for mobile operators", J. Advert. Res. March 2009, 5461.

Gauzente C (2008), "Le mobile marketing: etude exploratoire qualitative et quantitative des perceptions des consommateurs", $7^{\text {th }}$ Congress for Marketing Trends.

Gold J, Lim SC, Hellard ME, Hocking JS, Keogh L (2010), "What's in a message? Delivering sexual health promotion to young people in Australia via text messaging", BMC Public Health,10 (792):1-11.

Haghirian P, Madlberger M (2005). "consumer attitude toward advertising via mobile devices - an empirical investigation among Austrian users", Proceedings of European Conference on Information Systems (ECIS),.Regensburg, Germany, pp 1-12

Haig M (2002). Mobile marketing: the message revolution, Kogan Page Limited, London, 226P.

Heinonen K, Strandvik T. (2003). "Consumer responsiveness to mobile marketing", Stockholm Mobility Roundtable, Stockholm of 22 to 23 May 2003, read online on 7 May 2012 at link address http://web.hhs.se/cic/roundtable2003/papers/D22Heinonen_Strandvik .pdf.

Hsu CL, Lu HP, Hsu HH, (2007), "Adoption of the mobile internet: an empirical study of multimedia message service (MMS)", Inter .J. Manage. Sci. December 2007.

Huang YR (2011), "Value, interest and power: a three dimensional model for mobile marketing stakeholder analysis", Int. J. Mobile Market.6 (1): 109-119.

lacovou AL, Benbasat I, Dexter A (1995), "Electronic data interchange and small organizations: adoption and impact of technology", MIS Quarterly, 465-485.

Lee HH, Hill JT (2013), "Utilitarian and hedonic perceptions of short message service mobile marketing", Inter. J. Mobile Communicat.11 (6), 597-616.

Leppäniemi M, Karjaluoto $H$, Salo J (2004), "The success factors of mobile advertising value chain", E-Bus. Rev. Vol IV, pp 93-97

Leppaniemi M, Karjaluoto $H$ (2005). "Factors influencing consumers willingness to accept mobile advertising: a conceptual model", Int. J. Mobile Commun. 3(3): 197-213.

Leppäniemi M, Sinisalo J,Karjaluoto H (2006), "A review of mobile marketing research", Inter. J.Mobile Market.1(1): 30-40.

Lertwongsatien C, Wongpinunwatana N (2003), "E-Commerce adoption in Thailand: an empirical study of small and medium enterprises (SMEs)", J.Global Informat.Technol. Manage.6 (3):67-83.

Lindon D (1985), Le marketing, Fernand Nathan, 239 p.

MMA (Mobile Marketing Association) (2008), read on 23 September 2011 at the link address http://mmaglobal.com/wiki/mobile-marketing.
Mort GS, Drennan J (2002), "Mobile digital technology: emerging issues for marketing", J.Database Manage.10 (1): 9-23.

Okazaki S. (2005), "Mobile advertising adoption by multinationals: Senior executives' initial responses", Internet Res.15 (2): 160-180.

Okazaki S, Taylor RC (2008), "What is SMS advertising and why do multinationals adopt it? Answers from an empirical study in European markets", J. Bus.Res.61 (1): 4-12.

Rao S, Troshani I (2007), "A Conceptual Framework and Propositions for the Acceptance of Mobile Service", J. Theoret. Appl. Elect. Commerce Res. 2 (2): 61-73.

Rogers EM (1995), Diffusion of innovations, 4th edition, The Free Press, New York, 528P.

Scharl A, Dickinger A, Murphy J (2005), "Diffusion and success factors of mobile marketing", Elect. Commerce Res.Applicat.4: 159-173.

Sparling L, Toleman M, Cater-Steel A (2010), "SME adoption of ecommerce in the central Okanagan Region of Canada", Proceedings of the $18^{\text {th }}$ Australasian Conference on Information Systems, Toowoomba Australia, 1046-1059.

Tornatzky LG, Klein KJ (1982), "Innovation characteristics and innovation adoption implementation: a meta analysis of findings", IEEE Transactions on Engineering Management, EM-29(1), 28-45.

Tsang MM, Ho SC, Liang TP (2004), "Consumer attitudes toward mobile advertising: an empirical study", Inter. J.Elect. Commerce, 8(3): 65-78.

Varnali K, Toker A (2010). "Mobile marketing research: the state of the art", Int. J. Inform. Manage, 30: 144-151.

Vatanparast R (2010), "Mobile service adoption optimization: a case study", Inte J. Mobile Market. 5(2): 57-74.

Venkatesh W, Davis FD (2000). "A theoretical extension of the Technology Acceptance Model: four longitudinal field studies", Manage.Sci.42(2): 186-204.

Yin RK (2003), Applications of case study research, Applied Social Research Series, Second Edition, Vol 34, Sage Publications. 